\title{
Erratum to: A Predictive Model of Suitability for Minimally Invasive Parathyroid Surgery in the Treatment of Primary Hyperparathyroidism
}

Dara O. Kavanagh • Patricia Fitzpatrick • Eddie Myers • Rory Kennelly • Stephen J. Skehan • Robert G. Gibney • Arnold D. K. Hill • Denis Evoy • Enda W. McDermott

Published online: 2 March 2012

(c) Société Internationale de Chirurgie 2012

\section{Erratum to: World J Surg}

DOI 10.1007/s00268-011-1377-z

The corrected title of this article is as it appears in this erratum.

The online version of the original article can be found under doi:10.1007/s00268-011-1377-z.

D. O. Kavanagh $(\bowtie) \cdot$ E. Myers - R. Kennelly .

A. D. K. Hill · D. Evoy · E. W. McDermott

Department of Breast \& Endocrine Surgery,

St. Vincents University Hospital, Elm Park, Dublin 4, Ireland

e-mail: dara_kav@hotmail.com

P. Fitzpatrick

Department of Medicine, Physiotherapy \& Population Science, School of Public Health Medicine, University College Dublin, Belfield, Dublin 4, Ireland

P. Fitzpatrick

School of Medicine \& Medical Science,

University College Dublin, Belfield, Dublin 4, Ireland

S. J. Skehan · R. G. Gibney

Department of Radiology, St. Vincents University Hospital,

Elm Park, Dublin 4, Ireland 